\title{
Repository Corticotropin Injection for the Treatment of Pulmonary Sarcoidosis: A Narrative Review
}

\author{
Mehdi Mirsaeidi · Robert P. Baughman
}

Received: November 19, 2021 / Accepted: January 6, 2022 / Published online: February 3, 2022

(C) The Author(s) 2022

\section{ABSTRACT}

Although corticosteroids are the standard firstline therapy for pulmonary sarcoidosis, long-term and high-dose use of these drugs are associated with increased risk of adverse events and high healthcare utilization costs. Treatment guidelines for pulmonary sarcoidosis indicate that off-label immunomodulators and biologics may be warranted for severe disease. Repository corticotropin injection (RCI, Acthar ${ }^{\circledR}$ Gel), a complex mixture of adrenocorticotropic hormone analogs and other pituitary peptides, is one of only two therapies approved by the US Food and Drug Administration for symptomatic pulmonary sarcoidosis and is recommended by current European Respiratory Society treatment guidelines for use on a

M. Mirsaeidi

Division of Pulmonary and Critical Care, College of Medicine-Jacksonville, University of Florida,

Jacksonville, FL, USA

R. P. Baughman

University of Cincinnati Medical Center, 200 Albert

Sabin Way, Room 1001, Cincinnati, OH 45267, USA

M. Mirsaeidi $(\square)$

Clinical Center, 7Th Floor, 655 West 8th Street, C54, Jacksonville, FL 32209, USA

e-mail:m.mirsaeidi@ufl.edu case-by-case basis. With its unique anti-inflammatory and immunomodulatory mechanism of action through activation of melanocortin receptors in various cell types, RCI has demonstrated steroid-sparing properties. RCI has a long history of use in autoimmune and inflammatory disorders, with proven safety and efficacy for pulmonary sarcoidosis. In this narrative review, we present the clinical evidence for the safety and efficacy of RCI in the treatment of pulmonary sarcoidosis, identify where RCI falls within the current treatment guidelines, and describe the unique mechanism of action of RCI for promoting anti-inflammatory and immunomodulatory effects.

Keywords: Acthar Gel; Pulmonary; RCI; Repository corticotropin injection; Sarcoidosis 


\section{Key Summary Points}

This narrative review summarizes recent clinical practice guidelines on the treatment of pulmonary sarcoidosis, as well as mechanistic and clinical data supporting repository corticotropin injection (RCI) as a safe and effective treatment option.

Multiple therapeutic options exist, including methotrexate, azathioprine, leflunomide, mycophenolate, and infliximab; however, only corticosteroids and RCI are approved by the US Food and Drug Administration for the treatment of sarcoidosis.

RCI uniquely binds and activates melanocortin receptors on adrenocortical cells and various types of immune cells to promote anti-inflammatory and immunomodulatory effects.

RCI is steroid-sparing for patients with sarcoidosis, most of whom reduced their steroid dosages by $>50 \%$ in three clinical trials, and has been shown to be safe and effective for treatment of sarcoidosis that was nonresponsive to corticosteroids.

A recent expert panel using a modified Delphi process found that RCI is most commonly used in clinical practice as a second-line treatment for sarcoidosis after steroids, while European Respiratory Society (ERS) guidelines recommend that RCI be used on a case-by-case basis.

\section{INTRODUCTION}

Sarcoidosis is an inflammatory disorder characterized by granuloma formation that can affect any organ in the body, but it is most commonly observed in the lungs $[1,2]$. The prevalence of sarcoidosis in the US is estimated to be 60 per 100,000 adults and varies by geographical location, age, sex, and ethnicity, with African American women having the highest prevalence of 142 per 100,000 [3, 4]. Eighty to ninety percent of patients with sarcoidosis have lung or mediastinal lymph node involvement, which are characteristic of pulmonary sarcoidosis [4]. The prevalence of pulmonary sarcoidosis in Denmark and Sweden has been estimated at 48-68 per 100,000 [5].

The manifestations of sarcoidosis are highly variable, with the course of the disease often being unpredictable [6]. Although some patients with sarcoidosis have spontaneous remission without treatment, a large proportion of patients have substantial morbidity, with $5-10 \%$ of these cases resulting in death [7]. The mortality with sarcoidosis is generally attributable to major organ damage [7]. Pulmonary fibrosis contributes to more than half of sarcoidosis fatalities, and cardiac sarcoidosis is also a major contributor to sarcoidosis deaths [8]. Neurologic sarcoidosis is associated with extensive morbidity but low mortality [7].

Guidelines are available to aid practitioners in the diagnosis, detection, and treatment of sarcoidosis [9-13], including an official American Thoracic Society (ATS) clinical practice guideline [10] and the most recent European Respiratory Society (ERS) treatment guidelines [13]. For patients who have been diagnosed with pulmonary sarcoidosis and are considered candidates for treatment, the goal is to reduce granulomatous inflammation and prevent the development of irreversible organ damage (e.g., honeycombing and fibrotic lung disease) while avoiding excess toxicity from medications [14].

After expert recommendations using a modified Delphi process (a strategy for developing consensus based on expert opinion) for the treatment of sarcoidosis were published [15], an ERS Task Force committee developed a treatment algorithm with the evidence-based GRADE (Grading of Recommendations, Assessment, Development and Evaluations) methodology (Fig. 1) [13]. ERS recommendations include glucocorticoids as an initial therapy for sarcoidosis, although severe disease may warrant immunomodulators or biologics; rituximab, Janus kinase (JAK)-inhibitors, and repository corticotropin injection (RCI; Acthar ${ }^{\circledR}$ 


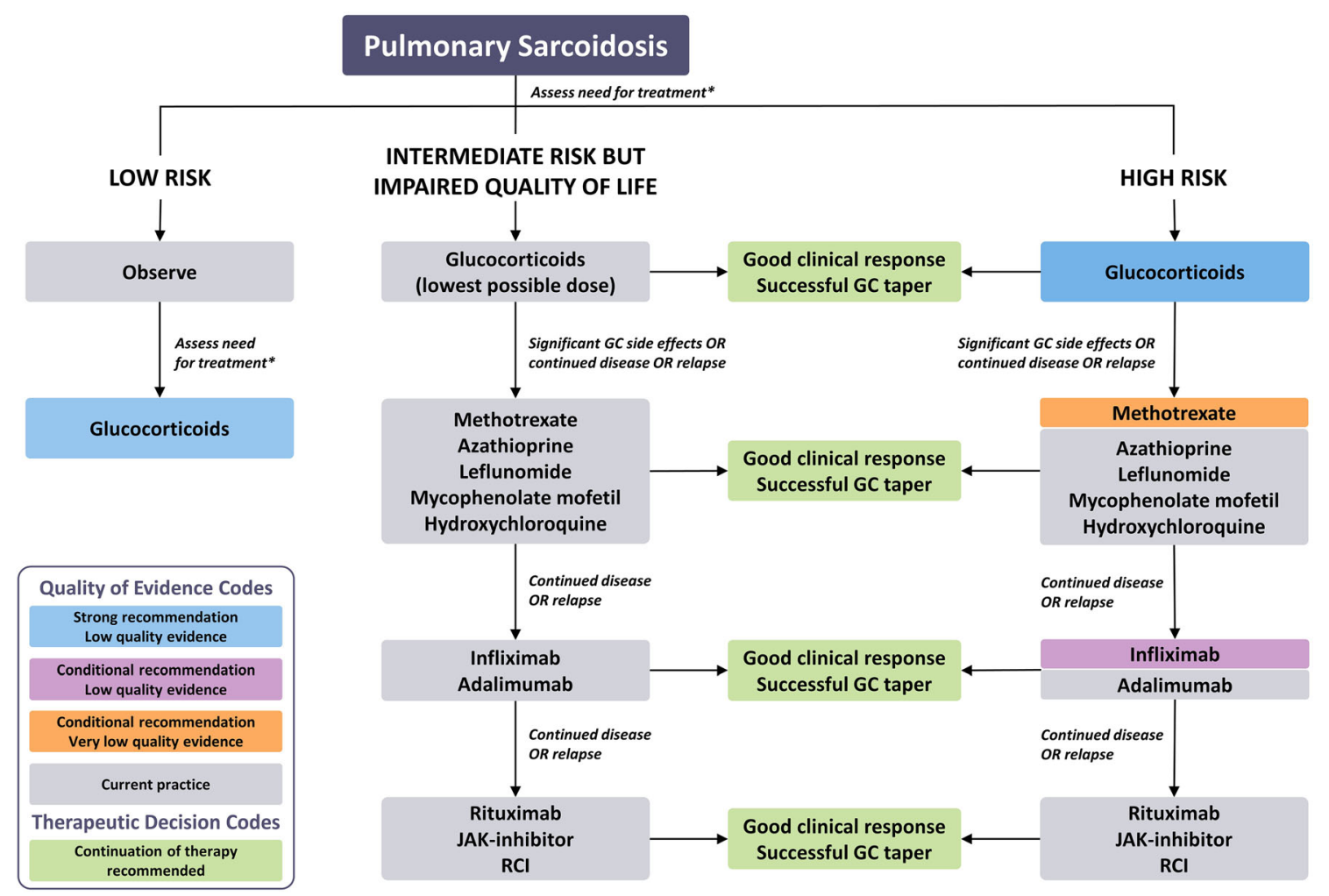

Fig. 1 Approach for pulmonary sarcoidosis. Use of rituximab, JAK-inhibitor, and RCI should be on a caseby-case basis. This figure is a combination of the recommendations made in the cited guidelines and a description of task force members' current practice in situations where there was not enough evidence to warrant a recommendation or for questions for which a systematic review of the literature was not undertaken.

Gel) should be considered on a case-by-case basis [13]. Of the treatments recommended for sarcoidosis, only corticosteroids (e.g., prednisone) and RCI are approved by the US Food and Drug Administration (FDA) for the treatment of symptomatic pulmonary sarcoidosis $[9,16]$, with limited evidence supporting the use of the other agents. However, evidence links long-term and high-dose corticosteroid use with increased risk of adverse events (AEs) and higher health care utilization costs $[17,18]$. The objective of this review manuscript is to provide an overview of the data on the mechanism of action of RCI as it relates to the pathophysiology of sarcoidosis, as well as the clinical data supporting the safety and efficacy of RCI for the treatment of sarcoidosis. This article is based on
Note that the information depicted as current practice (in grey color) is not intended as a recommendation for clinical practice. Abbreviations: $G C$ glucocorticoids, $J A K$ Janus kinase, $R C I$ repository corticotropin injection. Figure and Figure Legend were reproduced with permission of the ERS 2021: European Respiratory Journal. 2004079; https://doi.org/10.1183/13993003.04079-2020 Published 17 June 2021

previously conducted studies and does not contain any new studies with human participants or animals performed by any of the authors.

\section{Pathophysiology of Pulmonary Sarcoidosis}

Sarcoidosis is characterized by noncaseating granulomas in response to an exaggerated immune response (Fig. 2), with lung granulomas indicating pulmonary sarcoidosis $[19,20]$. Although the exact cause of sarcoidosis is unknown, cancer or exposure to mycobacteria or dust may trigger its presentation [6, 21, 22]. Expression of various inflammatory cytokines, including tumor necrosis factor (TNF)- $\alpha$ and 


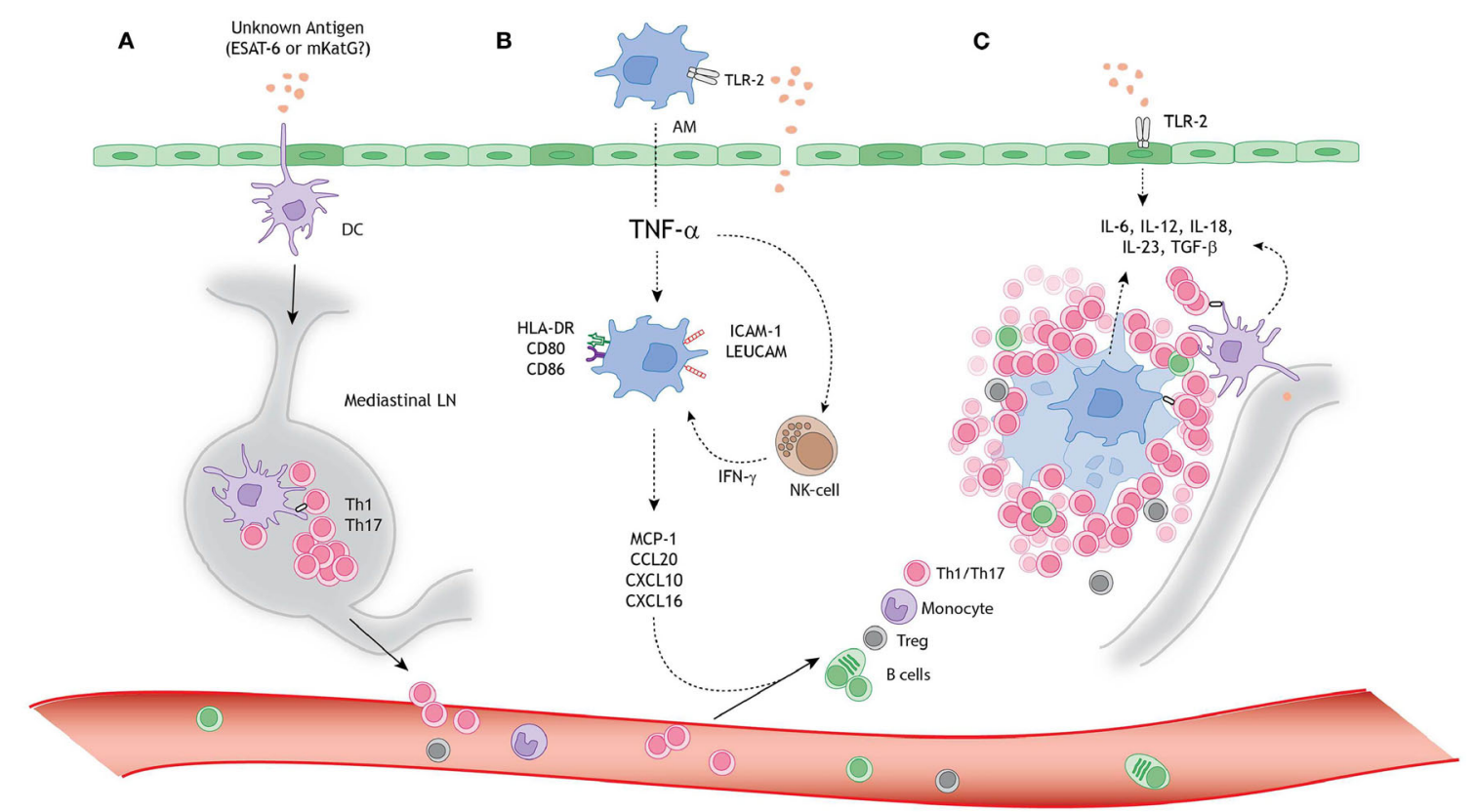

Fig. 2 A schematic model for granuloma formation in pulmonary sarcoidosis. An unknown airborne antigen activates A interstitial dendritic cells (DCs), B alveolar macrophages (AMs), and $\mathbf{C}$ alveolar epithelial cells type II (AEC-II) (dark green), simultaneously. This process is initiated by Toll-like receptor-2 (TLR-2) ligands, possibly Mycobacterium tuberculosis-derived ESAT-6 or mKatG. A The interstitial DCs pick up the putative antigen and migrate toward the mediastinal lymph nodes ( $\mathrm{LNs})$, where they initiate differentiation and clonal expansion of $T$ helper (Th) 1 and 17 cells. B Simultaneously, AMs produce tumor necrosis factor-alpha (TNF- $\alpha$ ), which initiates upregulation of activation (HLA-DR and CD80/86) and adhesion (ICAM-1 and LeuCAM) molecules. Macrophages produce chemokine ligands (MCP-1, CCL20, CXCL10, and CXCL16) under

interleukins, lead to the formation of granulomas [19]. Cytokines produced by Th1 cells (e.g., IL-2, IFN- $\gamma$ ) and Th2 cells (e.g., IL-6) are involved in progression to fibrosis $[19,23]$.

Melanocortin receptors (MCRs) are expressed in cells within granulomas, including macrophages, mast cells, T cells, and B cells [24]. MCRs are seven-transmembrane G-protein coupled receptors that have an anti-inflammatory effect by stimulating signaling pathways that inhibit expression of inflammatory cytokines $[25,26]$. stimulation of both TNF- $\alpha$ and natural-killer (NK) cellderived interferon-gamma (INF- $\gamma$ ), thereby attracting Th1/17 cells, monocytes, regulatory $\mathrm{T}$ cells (Tregs), and B cells. C The lung environment is characterized by the presence of Th1 and Th17 favoring cytokines, such as interleukin (IL)-6, IL-12, IL-18, IL-23, and TGF-beta (TGF- $\beta$ ) produced by macrophages, perilymphatic DCs, and AEC-II. Persistent stimulation, mediated by antigenpresenting cells (APCs), leads to continuous cellular recruitment to the site of inflammation, which leads to granuloma formation. Tregs infiltrating the granuloma fail to diminish the exaggerated immune response, thereby contributing to granuloma persistence and integrity. Figure and Figure Legend were accessed from Broos et al. [20] under the CC BY license Open Access agreement

\section{RCI and its Mechanism of Action}

RCI has been used since the 1950s to treat autoimmune and inflammatory conditions [16]. Although RCI is FDA-approved to treat such conditions, it is not approved for use outside the US. RCI is a naturally sourced complex mixture of adrenocorticotropic hormone (ACTH) analogs and other pituitary peptides [16]. The manufacturing process for RCI converts the initial porcine pituitary extract with low ACTH content into a mixture having modified porcine ACTH and other related 
peptide analogs solubilized in gelatin [16]. A major component in the formulated, complex mixture is N-25 deamidated (N25D) porcine ACTH (1-39) [16].

RCI is an agonist for all five MCRs [16]. MCR agonists are believed to modulate the hyperactive/dysregulated immune response in sarcoidosis $[25,27]$. The complex mixture of ACTH analogs and other pituitary peptides in RCI correspond to unique binding and functional activity on MCRs relative to stand-alone synthetic ACTH peptides [28]. In an in vitro study, RCI was determined to be a partial agonist at MC5R and a full agonist at MC1R, MC2R, MC3R, and MC4R [28]. Among the MCRs for which it is a full agonist, RCI has its lowest functional activity at MC2R [28]. Inversely, synthetic $\mathrm{ACTH}_{1-24}$ has its highest activity at MC2R [28]. RCI has higher potency at MC1R, MC2R, MC3R, and MC4R than its major component, $\mathrm{N} 25 \mathrm{D}-\mathrm{ACTH}_{1-39}$, as well as than $\mathrm{ACTH}_{1-24}$, which highlights this mixture's unique properties.

The anti-inflammatory effects of RCI were initially thought to be mediated indirectly through endogenous corticosteroid production following the engagement of MC2R on adrenocortical cells [29]. However, in animal studies, RCI induced significantly lower corticosterone levels than synthetic $\mathrm{ACTH}_{1-24}$, consistent with their respective functional activity at MC2R [28]. Pharmacologic studies in healthy human subjects have also demonstrated that RCI induces lower cortisol production than does synthetic $\mathrm{ACTH}_{1-24}$ depot at clinically relevant doses, further supporting that RCI has a unique mechanism of action [30, 31]. The lower cortisol response of RCI was achieved despite plasma concentrations of the pharmacokinetic marker of RCI (N25-deamidated porcine $\mathrm{ACTH}_{1-39}$ ) being higher than concentrations of $\mathrm{ACTH}_{1-24}$ [31].

Recent studies suggest that RCI may predominantly function through direct binding and activation of MCRs on other cell types (Fig. 3). RCI has been shown to directly modulate immune cells and various other cell types via interaction with MC1R, MC3R, MC4R, and MC5R [28, 32-34]. In vitro studies of stimulated human B cells isolated from blood [33], and spleen lymphocytes obtained from a murine model of systemic lupus erythmatosus [35] have shown that RCI inhibits proliferation of B cells and antibody production $[33,35]$. A study using a mouse model of multiple sclerosis suggested that RCI may shift pro-inflammatory Th1 cells to a more regulatory Th2/Treg phenotype [36]. Alveolar macrophages are activated and release TNF- $\alpha$ in bronchoalveolar lavages of patients with sarcoidosis, especially in those with worsening disease [37, 38].

Further understanding of MCR agonist mixtures such as RCI may be informed by research on individual MCR agonists including ACTH, $\alpha$ melanocyte-stimulating hormone $(\alpha-\mathrm{MSH}), \beta$ melanocyte-stimulating hormone ( $\beta$-MSH), and $\gamma$-melanocyte-stimulating hormone $(\gamma-\mathrm{MSH})$ [25]. $\alpha$-MSH acts through MC1R to reduce proinflammatory cytokines, as shown in a model of peripheral blood mononuclear cells derived from patients with confirmed treatment-naïve sarcoidosis [27]. This effect may be achieved by inducing phosphorylation of cyclic adenosine monophosphate-response element binding protein (CREB), as anti-inflammatory effects of $\alpha$-MSH were blocked by phospho-CREB inhibition [27]. $\beta$-MSH and $\gamma$-MSH have been studied less extensively, but $\beta$-MSH also binds to MC1R, MC3R, and MC4R; $\gamma$-MSH binds with low affinity to MC1R and MC4R and with similar binding affinity as other MCR agonists to MC3R [25]. MCR binding leads to activation of each receptor and subsequent inhibition of inflammation [25].

Anti-inflammatory effects of MCR agonists have been demonstrated in preclinical studies of pulmonary disease, including in an in vitro model of human sarcoidosis (challenged peripheral blood mononuclear cells from patients with sarcoidosis), which showed that RCI significantly reduced granuloma-associated increases in the inflammatory cytokines IL-1 $\beta$, IL-4, TNF- $\alpha$, and granulocyte-macrophage colony-stimulating factor (GM-CSF) [39]. Melanocortin peptides diminished airway inflammation through activation of MC3R and subsequent inhibition of TNF- $\alpha$ in a model of non-allergic pulmonary inflammation [40]. The MSH analogue STY39 reduced pro-inflammatory cytokines and attenuated pulmonary fibrosis in a murine model [41]. The 


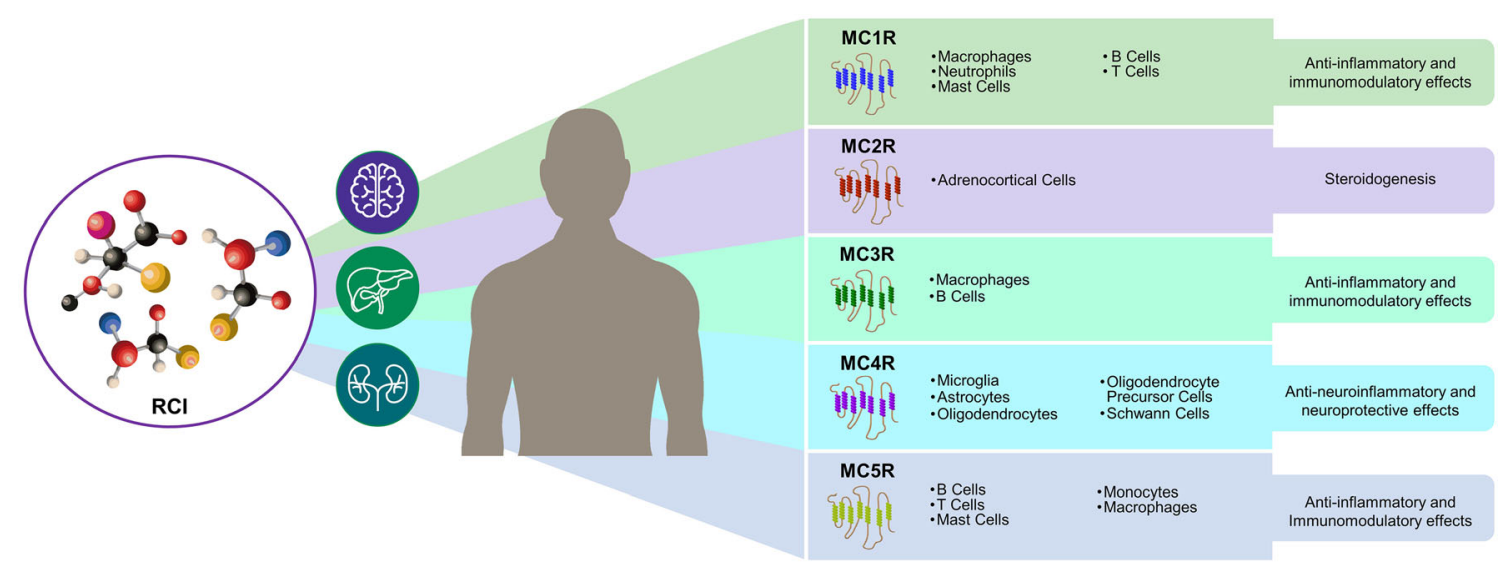

Fig. 3 Mechanism of action of RCI. Cell types and tissues affected by MCRs are described previously [24, 39-41]. Abbreviations: $A C T H$ adrenocorticotropic hormone, $M C R$ melanocortin receptor, $R C I$ repository corticotropin injection

immunomodulatory effects of RCI and related compounds via MCRs likely mitigate the pathophysiology of pulmonary sarcoidosis.

\section{Clinical Efficacy and Safety of RCI in Pulmonary Sarcoidosis}

Multiple studies have examined the safety and efficacy of RCI for sarcoidosis, with initial reports of efficacy in 1952 [42]. As with most drugs used for the treatment of sarcoidosis, the efficacy of RCI in patients with pulmonary sarcoidosis is mainly based on retrospective data. A retrospective pilot study found that in 29 patients with advanced sarcoidosis who received RCI for 6 months or more, 11 showed improvements, 16 remained stable, and two relapsed [43]. RCI was well tolerated in twothirds of patients [43]. RCI also showed steroidsparing effects; most patients were able to reduce their prednisone dose by $>50 \%$ (Fig. 4) [43].

A single-blind prospective study of 18 patients with chronic pulmonary sarcoidosis found that in the 16 patients who completed the study, RCI treatment was prednisone-sparing and associated with significant improvements in pulmonary function, chest imaging results, and patient-reported outcome measures over a 24-week period [44]. RCI $40 \mathrm{U}$ was not inferior to RCI $80 \mathrm{U}$ but was more tolerable [44]. Only one patient discontinued treatment due to adverse events [44]. RCI allowed most patients to decrease prednisone dose by $>50 \%$ (Fig. 4).

In further support of the safety and efficacy of RCI, a retrospective analysis of medical records for 302 patients with advanced symptomatic sarcoidosis found that RCI was a favorable treatment option [45]. According to physicians' assessments of change in patients' health status after RCI therapy, overall status improved in $95 \%$ of patients, overall symptoms in $73 \%$, lung function in $38 \%$, and inflammation in 33\% (Table 1) [45]. Overall use of concomitant medications decreased by $75 \%$ and use of corticosteroids declined by $79 \%$ from the 3 months before RCI use to 3 months after RCI use (Fig. 4) [45]. Mean corticosteroid dose decreased from $18.2 \mathrm{mg} /$ day at baseline to $9.9 \mathrm{mg} /$ day after 3 months of RCI use [45].

In a case study, RCI was successful in treating advanced sarcoidosis in a patient who experienced an autoimmune reaction to infliximab [46]. Sarcoidosis skin lesions, including lupus pernio, improved with RCI treatment, which was well tolerated in this case study [46].

An ongoing phase 4, multicenter, randomized, double-blind, placebo-controlled exploratory study (PulSAR) to assess the efficacy and safety of RCI in subjects with pulmonary sarcoidosis should provide additional evidence to further demonstrate the role of RCI in the management of sarcoidosis (ClinicalTrials.gov identifier: NCT03320070) [47]. In this trial, 


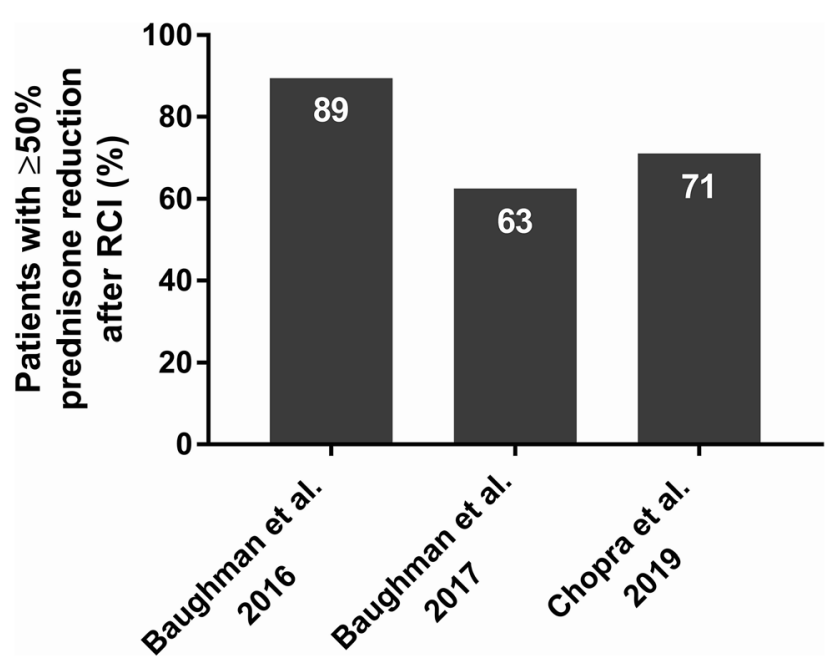

Fig. 4 Steroid-sparing effects of RCI in studies of patients with sarcoidosis. Studies mentioned on the $x$-axis of the graph refer to references [46-48]. Abbreviation: $R C I$ repository corticotropin injection

Table 1 Physicians' assessments of changes in patients' health following treatment with RCI $(n=302)$

\begin{tabular}{ll}
\hline Category & $n(\%)$ \\
\hline Patient's current status ${ }^{\mathrm{a}}$ & $288(95)$ \\
Improved & $14(5)$ \\
Not improved & $219(73)$ \\
Type of treatment response ${ }^{\mathrm{b}}$ & $116(38)$ \\
Overall symptoms & $100(33)$ \\
Lung function & $98(32)$ \\
Inflammation & $96(32)$ \\
Corticosteroid use (reduction or discontinuation) & $88(29)$ \\
Quality of life & $39(13)$ \\
Fatigue & $34(11)$ \\
Other organ functions & $29(10)$ \\
Pulmonary fibrosis & \\
Size of granulomas (inflamed lumps) & \\
\hline
\end{tabular}

Reproduced with permission from Chopra et al. [48]

aPhysicians' responses to the question, "What is the patient's status as of the end of RCI therapy or the 6 months point in therapy for ongoing treatment patients?”

'Physicians' responses to the survey, "Please select the outcomes below that have improved as a result of RCI treatment." Since respondents could select all options that applied, the sum exceeds $100 \%$

participants receive RCI or placebo subcutaneously twice weekly for 24 weeks; those receiving placebo will have the opportunity to receive RCI in the open-label extension period [47]. A composite score called the Sarcoidosis Treatment Score (STS) was previously developed 
to capture multiple facets of pulmonary sarcoidosis, which addresses an unmet need identified by a World Association of Sarcoidosis and Other Granulomatous disease (WASOG) task force [48]. Key outcomes in PulSAR include changes in elements of the STS, such as forced vital capacity (FVC), diffusing capacity of the lungs for carbon monoxide (DLCO), high-resolution computer tomography (HRCT), King's Sarcoidosis Questionnaire (KSQ), Fatigue Assessment Score (FAS), and corticosteroid taper $[47,48]$.

\section{Therapeutic Options for Pulmonary Sarcoidosis}

Corticosteroids are typically the mainstay of treatment for patients with symptomatic sarcoidosis [12, 15]. Although corticosteroids have been shown to improve chest X-rays over 3-24 months, there is little evidence of an improvement in lung function with these drugs [49]. Systemic therapy (usually corticosteroids) within the first 6 months of diagnosis is strongly associated with continued use 2 years later [50]. There are limited data beyond 2 years to indicate whether oral steroids have any modifying effect on long-term disease progression [49]. Long-term treatment with corticosteroids is associated with an increased risk of AEs [17] and a high rate of clinical relapse [51]. Corticosteroids are linked to cardiovascular risk factors and an increased incidence and progression of atheromatous vascular disease [52] as well as deleterious effects on glucose metabolism that can lead to insulin resistance and complicated diabetes $[53,54]$. Other side effects of corticosteroids include thrush, fluid retention, myopathy, osteoporosis, cataracts, and glaucoma [6].

Methotrexate is the most common antimetabolite used as a second-line therapy; it functions as a folate antimetabolite that inhibits DNA synthesis, repair, and replication [6]. Although methotrexate has been shown to effectively control pulmonary sarcoidosis $[38,55]$ and may have a steroid-sparing effect [55], there are major safety/toxicity concerns with all antimetabolite agents. Adverse events can include nausea/emesis, stomatitis, bone marrow suppression, and pneumonitis [6]. Methotrexate has a potential for hepatic and hematologic toxicity and is not recommended for those with renal insufficiency [7]. Relapses have been observed after discontinuation of methotrexate, which suggests that the drug's effects are suppressive rather than curative [55].

Azathioprine is also used as a second-line therapy, but it has increased risk of infections and potential malignancy [56]. Another therapy utilized for pulmonary sarcoidosis is leflunomide, but it has been associated with peripheral neuropathy [56]. Data for mycophenolate suggests that it may be beneficial for sarcoidosis, although it has primarily been studied for interstitial lung disease [56]. Adalimumab and rituximab are monoclonal antibodies that have shown efficacy for sarcoidosis in early studies [56].

The biological agent infliximab is a monoclonal neutralizing antibody against TNF- $\alpha$ [9]. Small, short-term studies have shown that infliximab effectively reduced sarcoidosis symptoms in patients who were nonresponsive to other treatments [9]. Infliximab may cause varying AEs, including abdominal pain, nausea, diarrhea, dyspepsia, headache, rash, pruritus, pharyngitis, sinusitis, sore throat, and infusion reactions, including severe anaphylaxis [9]. Infliximab also increases the risk of infection and may increase risk of metastasis of known cancers and, in rare instances, autoimmune and demyelinating disease [9]. One study found that $55 \%$ of patients with sarcoidosis receiving infliximab eventually discontinued treatment, with allergic reaction being the most common reason [57]. Hazard ratios showed significantly higher likelihood of discontinuing therapy due to infection with infliximab $(12.1, p=0.01)$ and adalimumab $(9.7, p=0.04)$ than with RCI [57].

RCI is distinct from corticosteroids, inhibitors of cell activation, proliferation, and migration (e.g., methotrexate, azathioprine, leflunomide, mycophenolate), TNF- $\alpha$ antagonists (e.g., adalimumab, infliximab), and anti-cluster of differentiation (CD)20 antibodies (i.e., rituximab) $[56,58,59]$. In other inflammatory conditions, such as systemic lupus erythematosus, idiopathic inflammatory 
myopathies, and rheumatoid arthritis, RCI has been found to be safe and effective for treatment of patients who were nonresponsive to corticosteroids [60-62]. The effectiveness of RCI in patients who are refractory to corticosteroids supports RCI's unique mechanism of action that is distinct from steroids.

Possible side effects of RCI may include change in glucose tolerance, hypertension, and increased appetite and weight gain $[60,61,63]$. These side effects are consistent with those seen with glucocorticoids [61]; this may be expected considering that endogenous production of cortisol from the adrenal cortex is one of the mechanisms of RCI, albeit at lower levels than observed with other MCR agonists [31]. However, RCI is multi-mechanistic in that it may also cause direct modulation of immune cells, such as B cells and macrophages, independently of steroids [28, 31]. This is supported by a recent systematic review showing distinct $\mathrm{AE}$ profiles between RCI and glucocorticoids in the treatment of rheumatoid arthritis [64]. Head-to-head studies are needed to distinguish the safety and efficacy of RCI vs. glucocorticoids in the treatment of pulmonary sarcoidosis.

Unlike methotrexate, infliximab, adalimumab, rituximab, and mycophenolate, RCI is FDA-approved for symptomatic sarcoidosis and has a long-standing history in the treatment of autoimmune and inflammatory disorders [16]. Taking the unique mechanism of action, favorable safety profile, and clinical history into account, RCI is expected to soon become an effective treatment option worldwide [65].

\section{Expert Opinions on RCI for Treatment of Pulmonary Sarcoidosis}

A panel of experts used a modified Delphi process to agree on a starting dose of $40 \mathrm{U}$ RCI twice weekly for patients with less severe disease and that the drug be continued at a maintenance dose (individualized for each patient) for those who responded, particularly those with chronic refractory sarcoidosis [65]. Concomitant steroids are recommended to be quickly tapered in patients receiving RCI, but concomitant use of immunosuppressive medications can be continued [65]. RCI should be down-titrated or discontinued if severe AEs arise or if management of AEs fail [65]. This panel of experts concluded that most patients with pulmonary sarcoidosis in their practices were started on RCI as a second-line therapy after steroids (Fig. 5) [65].

\section{Future Directions for Pulmonary Sarcoidosis}

Decisions to treat pulmonary sarcoidosis could be increasingly based on modern techniques such as risk stratification and assessment of biomarkers. The first-line, second-line, and third-line strategies for pulmonary sarcoidosis may be an outdated concept. Perhaps the best option for determining appropriate treatment would be through a personalized medicine approach. Disease and risk characteristics, side effect profiles, and patient preference should be taken into account [58]. Patients with AfroCaribbean ancestry and women, as well as those with multiorgan involvement, high TNF- $\alpha$ release, and soluble interleukin-2 receptor levels, may have higher risk of mortality and progression of sarcoidosis [6, 37, 66]. Positron emission tomography (PET) scans can also be used to determine who should be treated and to evaluate improvement after treatment with RCI [43].

In the future, biopsied lung tissue could be stained using antibodies specific for cell-surface receptors such as TNF- $\alpha$ receptors, MCRs, or CD20 receptors to guide treatment. Patients with expression of a particular receptor type in their affected lung tissue may be best suited for prescription of a corresponding agonists or antagonist for those receptors. For example, infliximab may be appropriate for patients whose biopsies have high levels of TNF- $\alpha$ receptors, rituximab for patients with enrichment of $\mathrm{CD}_{20} 0^{+} \mathrm{B}$ cells, and RCI for those with high levels of MCRs. However, antibody staining for therapeutic use is still in the early stages of research and is not currently used for guiding treatment. 


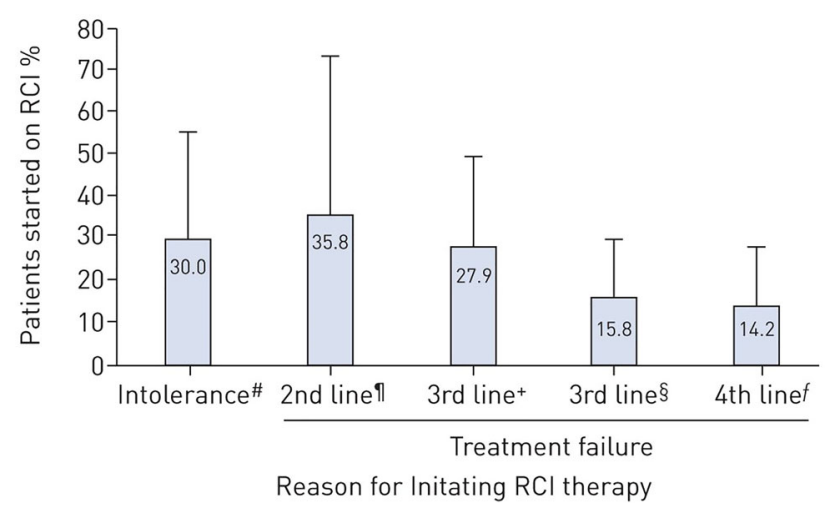

Fig. 5 Use of RCI for pulmonary sarcoidosis in clinical practice of participating panel experts. \#: to steroids, antimetabolites, or biologics; T: after steroids; + : after steroids and antimetabolites; $§$ : after steroids and biologics; $f$ :

\section{CONCLUSIONS}

Many recommended treatments for pulmonary sarcoidosis have shortcomings, including treatment failure, toxicity, and/or high discontinuation rates. Unlike most other therapies, RCI has a long-standing history in treating autoimmune and inflammatory disorders, proven safety and efficacy for pulmonary sarcoidosis and is FDA-approved to treat symptomatic sarcoidosis. A recent expert panel found that in clinical practice, RCI is most commonly used as a second-line treatment after steroids [65]. Individualized consideration of risk-benefit profiles is necessary for considering treatments for pulmonary sarcoidosis, including RCI.

\section{ACKNOWLEDGEMENTS}

Funding. This article and the journal's Rapid Service Fee were funded by Mallinckrodt Pharmaceuticals.

Medical Writing and/or Editorial Assistance. Professional writing and editorial support were provided by Nestor Davila, PhD, of MedLogix Communications, LLC, Itasca, Illinois, under the direction of the authors, and were funded by Mallinckrodt Pharmaceuticals. after steroids, antimetabolites, and biologics. $R C I$ repository corticotropin injection. Figure and Figure Legend were reproduced from Rahaghi et al. 2020 [65] under the https:// creativecommons.org/licenses/by-nc/4.0/

Authorship. Both authors meet the International Committee of Medical Journal Editors (ICMJE) criteria for authorship for this article, take responsibility for the integrity of the work as a whole, and have given their approval for this version to be published.

Author Contributions. Both authors were involved in the conception, design, critical evaluation, and editing of the manuscript, and have approved the final content.

Disclosures. Robert P. Baughman has received grant and research support from Actelion, AstraZeneca, aTyr Pharma, Bayer, Bellerophon Therapeutics, Boehringer Ingelheim, Celgene, Genentech, Gilead, Foundation for Sarcoidosis Research, Mallinckrodt Pharmaceuticals, Methelial, Novartis, and United Therapeutics. He has also received honoraria and consulting fees from Actelion, Genentech, KinBio, and Mallinckrodt Pharmaceuticals. Mehdi Mirsaeidi has nothing to disclose.

Compliance with Ethics Guidelines. This article is based on previously conducted studies and does not contain any new studies with human participants or animals performed by any of the authors.

Open Access. This article is licensed under a Creative Commons Attribution-NonCommercial 4.0 International License, which permits 
any non-commercial use, sharing, adaptation, distribution and reproduction in any medium or format, as long as you give appropriate credit to the original author(s) and the source, provide a link to the Creative Commons licence, and indicate if changes were made. The images or other third-party material in this article are included in the article's Creative Commons licence, unless indicated otherwise in a credit line to the material. If material is not included in the article's Creative Commons licence and your intended use is not permitted by statutory regulation or exceeds the permitted use, you will need to obtain permission directly from the copyright holder. To view a copy of this licence, visit http://creativecommons.org/licenses/by$\mathrm{nc} / 4.0 /$.

\section{REFERENCES}

1. Baughman RP, Teirstein AS, Judson MA, Rossman $\mathrm{MD}$, Yeager H Jr, Bresnitz EA, et al. Clinical characteristics of patients in a case control study of sarcoidosis. Am J Respir Crit Care Med. 2001;164(10 Pt 1):1885-9.

2. King TE. Clinical manifestations and diagnosis of pulmonary sarcoidosis. In: Post TW, editor. UpToDate. Waltham, MA: UpToDate; 2020.

3. Grunewald J, Grutters JC, Arkema EV, Saketkoo LA, Moller DR, Muller-Quernheim J. Sarcoidosis. Nat Rev Dis Primers. 2019;5(1):45.

4. Baughman RP, Field S, Costabel U, Crystal RG, Culver DA, Drent M, et al. Sarcoidosis in America. Analysis based on Health Care Use. Ann Am Thorac Soc. 2016;13(8):1244-52.

5. Milman N, Selroos O. Pulmonary sarcoidosis in the Nordic countries 1950-1982. Epidemiology and clinical picture. Sarcoidosis. 1990;7(1):50-7.

6. Aryal S, Nathan SD. Contemporary optimized practice in the management of pulmonary sarcoidosis. Ther Adv Respir Dis. 2019;13: 1753466619868935.

7. Baughman RP, Wells A. Advanced sarcoidosis. Curr Opin Pulm Med. 2019;25(5):497-504.

8. Mirsaeidi M, Machado RF, Schraufnagel D, Sweiss NJ, Baughman RP. Racial difference in sarcoidosis mortality in the United States. Chest. 2015;147(2): 438-49.

9. Baughman RP, Culver D, Drake W, Judson M, Maier L, Moller D, et al. Sarcoidosis treatment guidelines. 2010. Available from: https://www.stopsarcoidosis. org/treatment-protocol/. (Dec 21, 2021).

10. Crouser ED, Maier LA, Wilson KC, Bonham CA, Morgenthau AS, Patterson KC, et al. Diagnosis and detection of sarcoidosis. An official American Thoracic Society clinical practice guideline. Am J Respir Crit Care Med. 2020;201(8):e26-51.

11. Jeny F, Bouvry D, Freynet O, Soussan M, Brauner M, Planes C, et al. Management of sarcoidosis in clinical practice. Eur Respir Rev. 2016;25(140):141-50.

12. Soto-Gomez N, Peters JI, Nambiar AM. Diagnosis and management of sarcoidosis. Am Fam Physician. 2016;93(10):840-8.

13. Baughman RP, Valeyre $D$, Korsten $P$, Mathioudakis AG, Wuyts WA, Wells A, et al. ERS clinical practice guidelines on treatment of sarcoidosis. Eur Respir J. 2021;58(6):2004079.

14. King TE. Treatment of pulmonary sarcoidosis: initial therapy with glucocorticoids. In: Post TW, editor. UpToDate. Waltham, MA: UptoDate; 2020.

15. Rahaghi FF, Baughman RP, Saketkoo LA, Sweiss NJ, Barney JB, Birring SS, et al. Delphi consensus recommendations for a treatment algorithm in pulmonary sarcoidosis. Eur Respir Rev. 2020;29(155): 190146.

16. Labeling-Package Insert: Acthar Gel. https://www. accessdata.fda.gov/drugsatfda_docs/label/2021/ 008372s071lbl.pdf. Accessed January 21, 2022.

17. Rice JB, White AG, Johnson M, Wagh A, Qin Y, Bartels-Peculis L, et al. Quantitative characterization of the relationship between levels of extended corticosteroid use and related adverse events in a US population. Curr Med Res Opin. 2018;34(8): 1519-27.

18. Rice JB, White AG, Johnson M, Wagh A, Qin Y, Bartels-Peculis L, et al. Healthcare resource use and cost associated with varying dosages of extended corticosteroid exposure in a US population. J Med Econ. 2018;21(9):846-52.

19. Iannuzzi MC, Rybicki BA, Teirstein AS. Sarcoidosis. N Engl J Med. 2007;357(21):2153-65.

20. Broos CE, van Nimwegen $M$, Hoogsteden $H C$, Hendriks RW, Kool M, van den Blink B. Granuloma formation in pulmonary sarcoidosis. Front Immunol. 2013;4:437. 
21. Starshinova AA, Malkova AM, Basantsova NY, Zinchenko YS, Kudryavtsev IV, Ershov GA, et al. Sarcoidosis as an autoimmune disease. Front Immunol. 2019;10:2933.

22. Bonifazi M, Gasparini S, Alfieri V, Renzoni EA. Pulmonary Sarcoidosis. Semin Respir Crit Care Med. 2017;38(4):437-49.

23. Wahlstrom J, Katchar K, Wigzell H, Olerup O, Eklund A, Grunewald J. Analysis of intracellular cytokines in CD4+ and CD8+ lung and blood T cells in sarcoidosis. Am J Respir Crit Care Med. 2001;163(1):115-21.

24. Catania A, Lonati C, Sordi A, Carlin A, Leonardi P, Gatti S. The melanocortin system in control of inflammation. Sci World J. 2010;10:1840-53.

25. Moscowitz AE, Asif H, Lindenmaier LB, Calzadilla A, Zhang C, Mirsaeidi M. The importance of melanocortin receptors and their agonists in pulmonary disease. Front Med (Lausanne). 2019;6:145.

26. Ahmed TJ, Montero-Melendez T, Perretti M, Pitzalis C. Curbing inflammation through endogenous pathways: focus on melanocortin peptides. Int J Inflam. 2013;2013: 985815.

27. Zhang C, Chery S, Lazerson A, Altman NH, Jackson $\mathrm{R}$, Holt $\mathrm{G}$, et al. Anti-inflammatory effects of alpha$\mathrm{MSH}$ through p-CREB expression in sarcoidosis like granuloma model. Sci Rep. 2020;10(1):7277.

28. Huang YJ, Galen K, Zweifel B, Brooks LR, Wright AD. Distinct binding and signaling activity of Acthar Gel compared to other melanocortin receptor agonists. J Recept Signal Transduct Res. 2020;41(5):425-33.

29. Ross AP, Ben-Zacharia A, Harris C, Smrtka J. Multiple sclerosis, relapses, and the mechanism of action of adrenocorticotropic hormone. Front Neurol. 2013;4:21.

30. Wang X, Pham L, Poola N, Brooks LR, Due B. Comparison of steroidogenic exposure following the administration of repository corticotropin injection with a synthetic ACTH1-24 depot and methylprednisolone in healthy subjects. Clin Pharmacol Drug Dev. 2021;10(7):777-88.

31. Poola N, Due B, Wright D, Brooks LR, Zaman F. Pharmacokinetics and pharmacodynamics of repository corticotropin injection compared with synthetic ACTH1-24 depot and methylprednisolone in healthy subjects. Clin Pharmacol Drug Dev. 2021. https://doi.org/10.1002/cpdd.1020 (Epub ahead of print).

32. Wright D, Zweifel B, Sharma P, Galen K, Fitch R. Reduced steroidogenic activity of repository corticotropin injection (RCI) induces a distinct cytokine response following $\mathrm{T}$ cell activation in vivo (abstract AB0082). Ann Rheum Dis. 2019;78:1504.

33. Olsen NJ, Decker DA, Higgins P, Becker PM, McAloose CA, Benko AL, et al. Direct effects of $\mathrm{HP}$ Acthar Gel on human B lymphocyte activation in vitro. Arthritis Res Ther. 2015;17:300.

34. Benko AL, McAloose CA, Becker PM, Wright D, Sunyer T, Kawasawa YI, et al. Repository corticotrophin injection exerts direct acute effects on human B cell gene expression distinct from the actions of glucocorticoids. Clin Exp Immunol. 2018;192(1):68-81.

35. Decker DA, Grant C, Oh L, Becker PM, Young D, Jordan S. Immunomodulatory effects of H.P. Acthar Gel on B cell development in the NZB/W F1 mouse model of systemic lupus erythematosus. Lupus. 2014;23(8):802-12.

36. Cusick MF, Libbey JE, Oh L, Jordan S, Fujinami RS. Acthar gel treatment suppresses acute exacerbations in a murine model of relapsing-remitting multiple sclerosis. Autoimmunity. 2015;48(4):222-30.

37. Ziegenhagen MW, Benner UK, Zissel G, Zabel P, Schlaak M, Muller-Quernheim J. Sarcoidosis: TNFalpha release from alveolar macrophages and serum level of sIL-2R are prognostic markers. Am J Respir Crit Care Med. 1997;156(5):1586-92.

38. Baughman RP, Lower EE. The effect of corticosteroid or methotrexate therapy on lung lymphocytes and macrophages in sarcoidosis. Am Rev Respir Dis. 1990;142(6 Pt 1):1268-71.

39. Rovinski R, Tian R, Mirsaedi M. Repository corticotropin injection has demonstrated anti-inflammatory effects in in vitro model of sarcoidosis granuloma. Am J Respir Crit Care Med. 2021;203: A4264.

40. Land SC. Inhibition of cellular and systemic inflammation cues in human bronchial epithelial cells by melanocortin-related peptides: mechanism of KPV action and a role for MC3R agonists. Int J Physiol Pathophysiol Pharmacol. 2012;4(2):59-73.

41. Xu PB, Mao YF, Meng HB, Tian YP, Deng XM. STY39, a novel alpha-melanocyte-stimulating hormone analogue, attenuates bleomycin-induced pulmonary inflammation and fibrosis in mice. Shock. 2011;35(3):308-14.

42. Miller MA, Bass HE. Effect of Acthar-c (ACTH) in sarcoidosis. Ann Intern Med. 1952;37(4):776-84.

43. Baughman RP, Barney JB, O'Hare L, Lower EE. A retrospective pilot study examining the use of 
Acthar gel in sarcoidosis patients. Respir Med. 2016;110:66-72.

44. Baughman RP, Sweiss N, Keijsers R, Birring SS, Shipley R, Saketkoo LA, et al. Repository corticotropin for chronic pulmonary sarcoidosis. Lung. 2017; 195(3):313-22.

45. Chopra I, Qin Y, Kranyak J, Gallagher JR, Heap K, Carroll S, et al. Repository corticotropin injection in patients with advanced symptomatic sarcoidosis: retrospective analysis of medical records. Ther Adv Respir Dis. 2019;13:1753466619888127.

46. Zhou Y, Lower EE, Li H, Baughman RP. Sarcoidosis patient with lupus pernio and infliximab-induced myositis: response to Acthar gel. Respir Med Case Rep. 2016;17:5-7.

47. Acthar Gel in Participants With Pulmonary Sarcoidosis (PULSAR). ClinicalTrials.gov identifier: NCT03320070. Available from: https:// clinicaltrials.gov/ct2/show/NCT03320070. (Dec 21, 2021).

48. Baughman RP, Tillinger M, Qin Y, Sweiss N, Lower EE. A composite score to assess treatment response in pulmonary sarcoidosis: the Sarcoidosis Treatment Score (STS). Sarcoidosis Vasc Diffuse Lung Dis. 2019;36(1):86-8.

49. Paramothayan NS, Lasserson TJ, Jones PW. Corticosteroids for pulmonary sarcoidosis. Cochrane Database Syst Rev. 2005;2010(2):CD001114.

50. Baughman RP, Judson MA, Teirstein A, Yeager $H$, Rossman M, Knatterud GL, et al. Presenting characteristics as predictors of duration of treatment in sarcoidosis. QJM. 2006;99(5):307-15.

51. Gottlieb JE, Israel HL, Steiner RM, Triolo J, Patrick $\mathrm{H}$. Outcome in sarcoidosis. The relationship of relapse to corticosteroid therapy. Chest. 1997;111(3):623-31.

52. Walker BR. Glucocorticoids and cardiovascular disease. Eur J Endocrinol. 2007;157(5):545-59.

53. Di Dalmazi G, Pagotto U, Pasquali R, Vicennati V. Glucocorticoids and type 2 diabetes: from physiology to pathology. J Nutr Metab. 2012;2012: 525093.

54. Xie W, Yang X, Ji L, Zhang Z. Incident diabetes associated with hydroxychloroquine, methotrexate, biologics and glucocorticoids in rheumatoid arthritis: a systematic review and meta-analysis. Semin Arthritis Rheum. 2020;50(4):598-607.

55. Fang C, Zhang Q, Wang N, Jing X, Xu Z. Effectiveness and tolerability of methotrexate in pulmonary sarcoidosis: a single center real-world study. Sarcoidosis Vasc Diffuse Lung Dis. 2019;36(3):217-27.

56. Culver DA, Judson MA. New advances in the management of pulmonary sarcoidosis. BMJ. 2019;367: I5553.

57. Lower EE, Sturdivant M, Grate L, Baughman RP. Use of third-line therapies in advanced sarcoidosis. Clin Exp Rheumatol. 2019;38(5):834-40.

58. Gerke AK. Treatment of sarcoidosis: a multidisciplinary approach. Front Immunol. 2020;11: 545413.

59. El Jammal T, Jamilloux Y, Gerfaud-Valentin M, Valeyre D, Seve P. Refractory sarcoidosis: a review. Ther Clin Risk Manag. 2020;16:323-45.

60. Askanase AD, Zhao E, Zhu J, Bilyk R, Furie RA. Repository corticotropin injection for persistently active systemic lupus erythematosus: results from a phase 4, multicenter, randomized, double-blind, placebo-controlled trial. Rheumatol Ther. 2020;7(4):893-908.

61. Fleischmann R, Furst DE, Connolly-Strong E, Liu J, Zhu J, Brasington R. Repository corticotropin injection for active rheumatoid arthritis despite aggressive treatment: a randomized controlled withdrawal trial. Rheumatol Ther. 2020;7(2): 327-44.

62. Saygin D, Oddis CV, Marder G, Moghadam-Kia S, Nandkumar P, Neiman N, et al. Follow-up results of myositis patients treated with H. P. Acthar gel. Rheumatology (Oxford). 2020;59(10):2976-81.

63. Furie R, Mitrane M, Zhao E, Das M, Li D, Becker PM. Efficacy and tolerability of repository corticotropin injection in patients with persistently active SLE: results of a phase 4 , randomised, controlled pilot study. Lupus Sci Med. 2016;3(1): e000180.

64. Fleischmann R, Furst DE. Safety of repository corticotropin injection as an adjunctive therapy for the treatment of rheumatoid arthritis. Expert Opin Drug Saf. 2020;19(8):935-44.

65. Rahaghi FF, Sweiss NJ, Saketkoo LA, Scholand MB, Barney JB, Gerke AK, et al. Management of repository corticotrophin injection therapy for pulmonary sarcoidosis: a Delphi study. Eur Respir Rev. 2020;29(155): 190147.

66. Bradley B, Branley HM, Egan JJ, Greaves MS, Hansell DM, Harrison NK, et al. Interstitial lung disease guideline: the British Thoracic Society in collaboration with the Thoracic Society of Australia and New Zealand and the Irish Thoracic Society. Thorax. 2008;63(Suppl 5):v1-58. 